\title{
REOXIDATION OF DIRECT REDUCED IRON IN STAGNANT AIR IN THE TEMPERATURE RANGE BETWEEN 150 AND $450^{\circ} \mathrm{C}$.
}

\author{
Abd Elmomen, S. S. ${ }^{*},+$ \\ *Associate Professor of Ferrous Metallurgy. Tabbin Institute for Metallurgical Studies. Tabbin, \\ P.O. Box: 109 Helwan, 11421 Cairo, Egypt. \\ † E-mail address: sanaa.said@hotmail.com
}

\begin{abstract}
Reoxidation of DRI in stagnant air in the temperature range between 150 and $450^{\circ} \mathrm{C}$ has been investigated. The aim is to contribute to the kinetics of reoxidation of hot DRI on transportation from a direct reduction plant to an EAF in case of leakage in the transportation vessel. Two series of experiments were conducted in a low temperature range between 150 and $250^{\circ} \mathrm{C}$ and in a higher range from 300 to $450^{\circ} \mathrm{C}$. At low temperature, the reaction rate is controlled by the chemical reaction at the gas-metal interface, whereas at higher temperatures, it (the reaction rate) is governed by pore diffusion. The activation energy of the chemical reaction is $59.7 \mathrm{~kJ} / \mathrm{mol}$ and for pore, diffusion is $18.04 \mathrm{~kJ} / \mathrm{mol}$. The diffusion coefficient increases with the $T^{3.359}$ to $T^{3.388}$. Empirical equations have been derived. Calculated data are in satisfactory agreement with corresponding practical results.
\end{abstract}

\section{Keywords}

Hot DRI; reoxidation; stagnant air; chemical reaction; pore diffusion.

\section{INTRODUCTION}

Steelmaking based on melting direct reduced iron (DRI) in electric arc furnace (EAF) is steadily expanding in countries having abundant reserves of natural gas. Middle East and North African Countries are increasingly using this technology. Because of the growing demand for high quality steel and the increasing prices of steel scrap, the world production of DRI grew from 59.70 to $72.76 \mathrm{Mt}$ in 2006 and 2016 respectively. The production of Middle East and North Africa increased from 16.04 to 34.19 Mt in the same period. In 2016, the world DRI production by the two well-established shaft furnace processes, Midrex and HYL/Energiron, was 59.80 Mt. The shares of the two technologies were 78.8 and $21.20 \%$ for Midrex and HYL/Energiron respectively. Other processes, e.g., fluidized bed, rotary kiln and others, achieved the rest of the world DRI production, which amounts to $12.96 \mathrm{Mt}$. A detailed survey on DRI production is available in the literature [1].

DRI pellets and hot briquetted iron (HBI) can also be used as part of blast furnace burden in order to improve the economics of this process [2-9].

The high porosity of DRI is the main reason for its high sensitivity towards reoxidation. The heat generated by reoxidation of cold discharged DRI stockpiled in air at ambient temperature led in many cases to spontaneous ignition and fire hazards.

Numerous research works have been done to study the problem of DRI reoxidation and suggest proposals for avoiding or minimizing its effects [10-14]. 
In recent years, there has been a steadily increasing trend to discharge hot direct reduced iron (HDRI) from shaft furnace and transport it hot to an EAF that is close to the direct reduction furnace to be melted to steel. This provides an optimal way in case of using DRI for steel manufacture by increasing productivity; saving energy and reducing production cost [15-18].

In spite of the importance of studying the kinetics of reoxidation of HDRI during transportation from the direct reduction furnace to the EAF, e.g. as a result of leakage in the transportation vessel, few investigations have been carried out in this direction.

The aim of the present research is to simulate and study the kinetics of HDRI reoxidation in stagnant air at temperatures between 150 and $450^{\circ} \mathrm{C}$.

\section{EXPERIMENTAL}

The experiments were conducted in a muffle furnace using DRI pellets produced in a commercially working plant. The furnace was preheated to about 3 to $5^{\circ} \mathrm{C}$ above the desired test temperature, in order to cover the heat loss caused by opening the door for inserting the pellets. The heating element was kanthal wire embedded in the refractory lining surrounding all the interior sides of the furnace. The dimensions of the heating chamber of the furnace were $9.5 * 28 * 39 \mathrm{~cm}^{3}$. The average pellet radius and density are $0.6121 \mathrm{~cm} 0.0429 \mathrm{~mol} \mathrm{Fe} / \mathrm{cm}^{3}$ respectively. For each time interval 3 pellets, were taken from a desiccator, weighed, put in separate baskets made of $\mathrm{Ni} \mathrm{Cr}$ wire and fixed to the ceramic tube of a Ni Cr-Ni thermocouple used to measure and control the temperature. The distance between pellets and thermocouple was about $3 \mathrm{~cm}$. The measured temperature was that of air inside the furnace. The door of the furnace was not tightly closed; only a very narrow space of about $1 \mathrm{~cm}$ between the door and the furnace body was left to allow the passage of a small quantity of air, which is necessary for DRI reoxidation. Immediately after elapse of the desired time interval at a given temperature, the furnace was opened and the pellets were carefully removed, cooled in a desiccator and weighed again. The degree of reoxidation was calculated from the weight gain.

Two series of experiments were made; the first was conducted at 150,200 and $250^{\circ} \mathrm{C}$, and the second was carried out at $300,350,400$ and $450^{\circ} \mathrm{C}$. The time intervals in the first series were 60, 90,120 and $180 \mathrm{~min}$; in the second series, these intervals were 10, $15,20,30$ and 45 minutes. A sketch of the experimental set up is given in figure 1 .

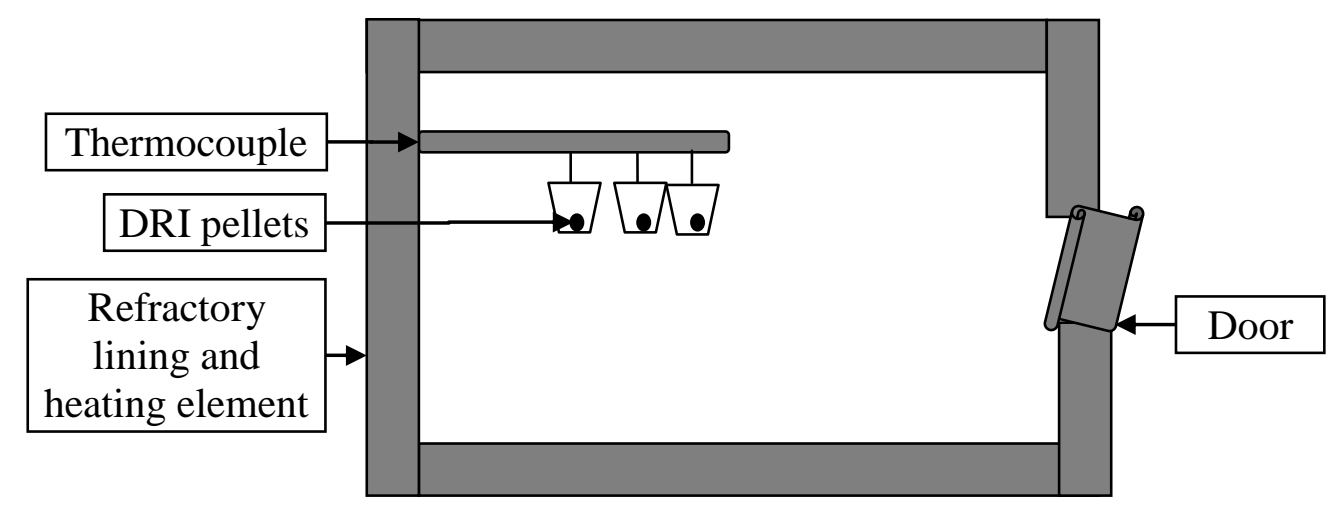

Fig. 1: Sketch of the experimental set up. 
The average chemical composition and physical properties of the DRI pellets used in the experiments are given in table 1 .

Table (1): Average chemical analysis (wt-\%) and physical properties DRI pellets.

\begin{tabular}{|c|c|c|c|c|c|c|c|c|}
\hline$\sum \mathbf{F e}$ & $\begin{array}{c}\text { Metallic } \\
\text { Fe }\end{array}$ & FeO & Gangue & Metallization & $\mathbf{C}$ & $\begin{array}{c}\text { True } \\
\text { density/ } \\
\mathbf{g ~ c m}^{-3}\end{array}$ & $\begin{array}{c}\text { Apparent } \\
\text { density/g } \\
\mathbf{c m}^{-3}\end{array}$ & $\begin{array}{c}\text { Porosity/ } \\
\mathbf{\%}\end{array}$ \\
\hline 92.34 & 88.51 & 4.93 & 4.71 & 95.85 & 1.85 & 5.6944 & 2.9303 & 48.54 \\
\hline
\end{tabular}

\section{RESULTS AND DISCUSSION}

The reoxidation reaction is assumed to be a heterogeneous irreversible gas-solid reaction of first order taking place in a topochemical form according to the shrinking core model. The reaction may be represented as follows:

$$
A_{(g)}+b B_{(s) \rightarrow p r o d u c t}
$$

The geometrical shape, size and density of the DRI pellets are assumed to remain unchanged after reoxidation.

Figure 2 shows a photomicrograph of a partially reoxidized DRI pellet treated at $450^{\circ} \mathrm{C}$ for 45 minutes. The topochemical structure is obvious, which substantiates the application of the shrinking core model to the problem at hand.

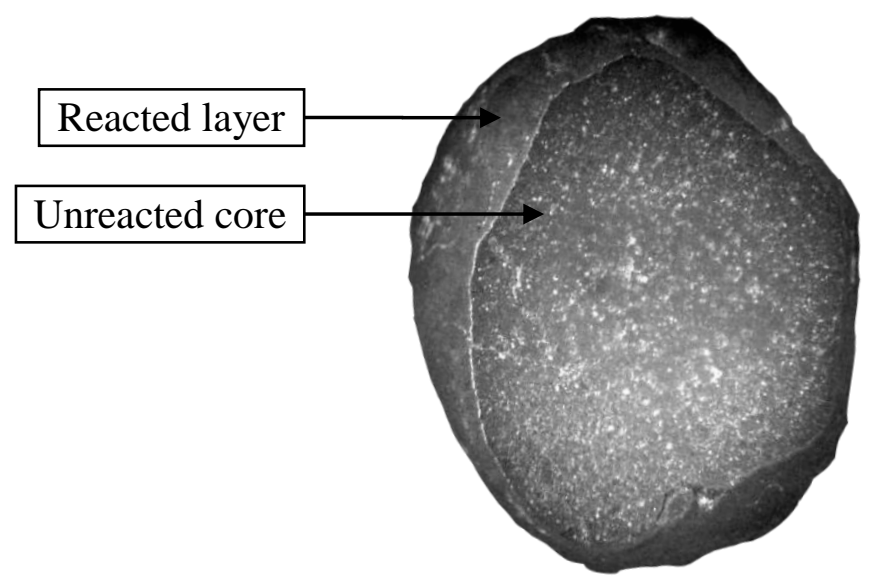

Fig. 2: Photomicrograph of a partially reoxidized DRI pellet treated at $450^{\circ} \mathrm{C}$ for 45 minutes.

The mechanism of DRI- pellets reoxidation according to the shrinking core model can be described by the following five main steps [19]:

1. External or surface diffusion of the reactant gas from the bulk gas phase through a boundary gas film to the surface of the pellet.

2. Internal diffusion of the gas through the pores of the oxide layer formed by reoxidation to the unreacted core of the pellet.

3. Chemical reaction between reactant gas and metal takes place at the gas-core interface. 
4. The gas produced, if available, diffuses through the oxide to the exterior of the pellet.

5. External diffusion of the product gas through the gas film to the bulk of the reacting gas phase.

Steps 4 and 5 may be disregarded in the present case since the reaction product is only solid iron oxide. It is important to find out the step that is responsible for determining the overall rate of the reoxidation process. In order to achieve this, two series of experiments were conducted; the first was done in the temperature range between 150 and $250^{\circ} \mathrm{C}$ and the second was run between 300 and $450^{\circ} \mathrm{C}$. In the first series, DRI pellets were treated for three hours in intervals of 30, 60, and 90 and 180 minutes; at $150^{\circ} \mathrm{C}$ an interval of 120 minutes was also included.

\subsection{Temperature range 150 to $250^{\circ} \mathrm{C}$}

In the relatively low temperature range, convective and pore diffusion are so rapid that slow chemical reaction at the interface controls the whole reaction rate. If the limiting step of the reoxidation process is the chemical reaction at the interface between air and metal then a straight line should be obtained when the reaction time, $\tau$, is plotted against $1-(1-\alpha)^{1 / 3}$ according to the equations $20-24$.

$$
\tau=\frac{r_{o} * \rho}{b k C g}\left[1-(1-\alpha)^{\frac{1}{3}}\right]
$$

$\rho:$ density of metallic iron in the pellet $\left(\mathrm{mol} / \mathrm{cm}^{3}\right)$

$r_{o}$ : initial radius of the DRI pellet $(\mathrm{cm})$

$b$ : number of moles of $\mathrm{O}_{2}$ needed to reoxidize one mole of $\mathrm{Fe}$ to $\mathrm{Fe}_{2} \mathrm{O}_{3}$ according to the reaction

$$
\mathrm{Fe}+\frac{3}{4} \mathrm{O}_{2} \rightarrow \frac{1}{2} \mathrm{Fe}_{2} \mathrm{O}_{3}
$$

$k$ : rate constant $(\mathrm{cm} / \mathrm{min})$

$C_{g}$ : concentration of $\mathrm{O}_{2}$ in air at the corresponding temperature $=\frac{0.21}{82.06}\left(\frac{\mathrm{mol}}{\mathrm{cm}^{3}}\right)$

$\alpha$ : degree of reoxidation $=\frac{\text { weight of oxygen gained by reoxidation }}{\text { weight of oxygen required to converts metallic } \mathrm{Fe} \text { and } \mathrm{FeO} \mathrm{toFe}_{2} \mathrm{O}_{3}}$

A graphical representation of equation 2 is given in figure 3. The straight lines indicate the validity of applying this equation to the present case. They can be described by the following equations:

$$
\begin{gathered}
\tau_{150=499245\left[1-(1-\alpha)^{1 / 3}\right], r=0.9822} \\
\tau_{200=} 79874\left[1-(1-\alpha)^{1 / 3}\right], r=0.9899 \\
\tau_{250=} 24307\left[1-(1-\alpha)^{1 / 3}\right], r=0.9901
\end{gathered}
$$




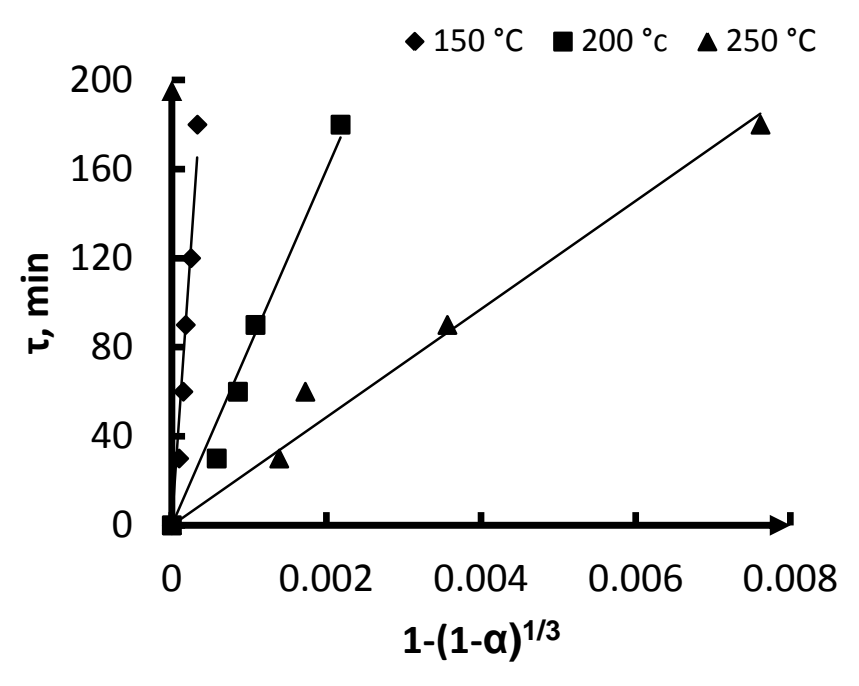

Fig. 3: Variation of time in minute with $1-(1-\alpha)^{1 / 3}$.

Using the slopes of the straight lines equations 5 to 7 and the slope of the line as given by equation 2 , the values of the apparent rate constant, $k$, can be estimated. Figure 4 depicts the variation of $\ln k$ with 10000/T according to Arrhenius equation. The straight line satisfies the formula:

$$
\begin{aligned}
\ln k & =12.5631-\frac{71800}{T}, r=0.9984 \\
k & =2.85827 * 10^{5} * \exp \left(-\frac{59700}{R T}\right)
\end{aligned}
$$

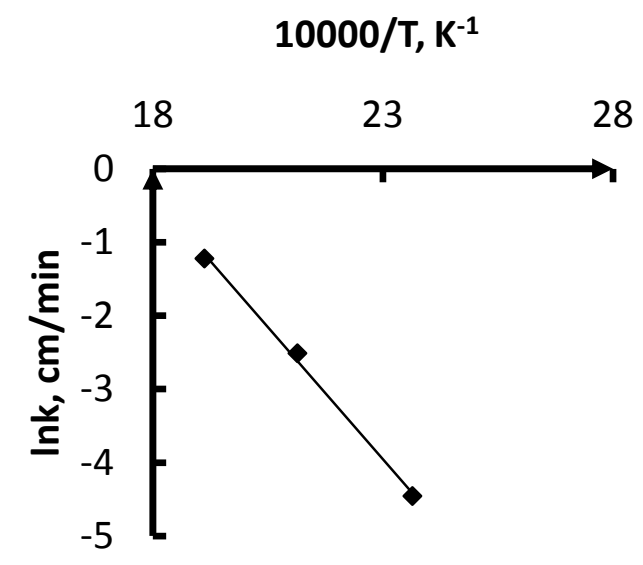

Fig. 4: Variation of $\ln \mathrm{k}$ with $10000 / \mathrm{T}$ according to Arrhenius equation. 
Therefore, the apparent activation energy of the reoxidation reaction in the temperature range between 150 and $250^{\circ} \mathrm{C}$ is $59.7 \mathrm{KJ} / \mathrm{mole}$, which compares with 57.0 and 62.0 $\mathrm{kJ} / \mathrm{mole}$ found elsewhere for the reoxidation reaction [25]. This indicates that chemical reaction controls reoxidation in this temperature range. Comparison of experimental data with calculated lines obtained by using equation 2 and substituting for, $k$, from equation 9 is shown in figure 5. It can be observed that measured data are in good agreement with the calculated lines, which supports the use of chemical model at low temperature.

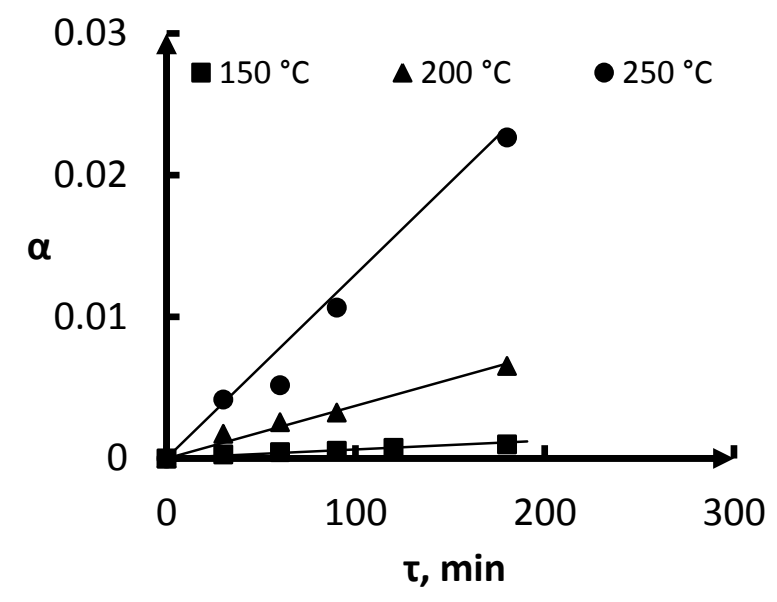

Fig. 5: Comparison of experimental data with calculated lines for the temperatures 150,200 and $250^{\circ} \mathrm{C}$ according to the chemical model.

\subsection{Temperature range 300 to $450^{\circ} \mathrm{C}$}

In order to find out which step controls the reoxidation process in the temperature range between 300 and $450^{\circ} \mathrm{C}$, surface diffusion, chemical reaction and pore diffusion are examined [20-24].

\subsubsection{Surface (external) diffusion}

In the case of surface diffusion, the following model is used:

$$
\tau=\frac{r_{o} * \rho}{3 b \beta C g} \alpha
$$

Assuming constant $\rho, \beta, r_{o}$ and $c_{g}$ at a given temperature, a plot of $\tau$ against $\alpha$ should give a straight line if surface diffusion controls reoxidation. The mass transfer coefficient, $\beta$, can be calculated using the slope of the line. The equations describing the straight lines at $300,350,400$ and $450^{\circ} \mathrm{C}$, as shown in figure 6 , are respectively.

$$
\begin{array}{cc}
\tau_{300}=109.6259 * \alpha, & r=0.9376 \\
\tau_{350}=93.8468 * \alpha, & r=0.8407 \\
\tau_{400}=84.3337 * \alpha, & r=0.8258 \\
\tau_{450}=78.7418 * \alpha, & r=0.8439
\end{array}
$$




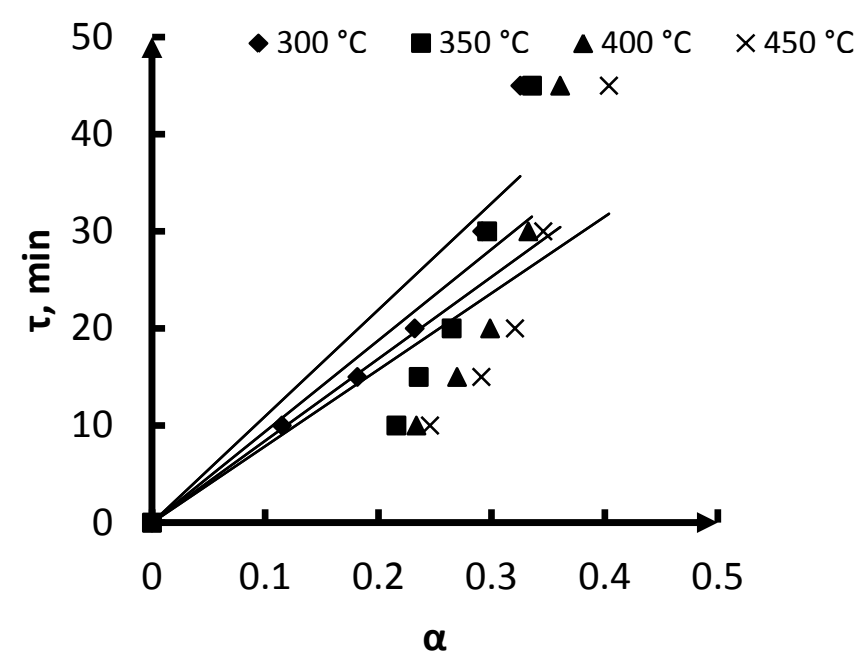

Fig. 6: Variation of time, in minute, with $\alpha$ at $300,350,400$ and $450^{\circ} \mathrm{C}$.

The mass transfer coefficient, $\beta$, can be estimated by using equations 10 to 14 . Since:

$$
\beta=\frac{D}{\delta}
$$

The thickness of the gas boundary layer surrounding the pellet, $\delta$, can be calculated.

$D$ is the diffusion coefficient of oxygen in the gaseous boundary layer and can be calculated according to:[26]

$$
D_{O_{2} / \text { air }}=\frac{\left(1 * 10^{-3}\right) T^{1.75}}{P\left(v_{\text {air }}^{1 / 3}+v_{O_{2}}^{1 / 3}\right)^{2}} \sqrt{\frac{1}{M_{O_{2}}}+\frac{1}{M_{\text {air }}}} \mathrm{cm}^{2} / \mathrm{s}
$$

where $v_{\text {air }}=20.1, v_{\mathrm{O}_{2}}=16.6, M_{\mathrm{O}_{2}}=32, M_{\text {air }}=29$

The thickness of the gas boundary layer varies with temperature as follows:

$$
\delta=-0.0016 * T+2.4502, \quad r=0.9565
$$

The large value of $\delta$ is the result of air stagnation in the furnace.

It should be mentioned that the Sherwood Number of ball $(2 \mathrm{ro} / \delta)$ in still flow is theoretically two [27].

\subsubsection{Chemical Reaction}

Assuming that chemical reaction controls reoxidation, then equation 2 can be applied.

A plot of, $\tau$, versus $1-(1-\alpha)^{1 / 3}$ should result in a straight line having a slope equal to $\frac{r_{o} * \rho}{b k C g}$ which can be used for estimating the rate constant of the chemical reaction. The straight lines are shown in figure 7; they may be described by the following equations at the temperatures $300,350,400$ and $450^{\circ} \mathrm{C}$. 


$$
\begin{array}{ll}
\tau_{300}=297.6903 *\left[1-(1-\alpha)^{1 / 3}\right], & r=0.9495 \\
\tau_{350}=254.3146 *\left[1-(1-\alpha)^{1 / 3}\right], & r=0.8592 \\
\tau_{400}=225.7009 *\left[1-(1-\alpha)^{1 / 3}\right], & r=0.8452 \\
\tau_{450}=208.3957 *\left[1-(1-\alpha)^{1 / 3}\right], & r=0.8669
\end{array}
$$

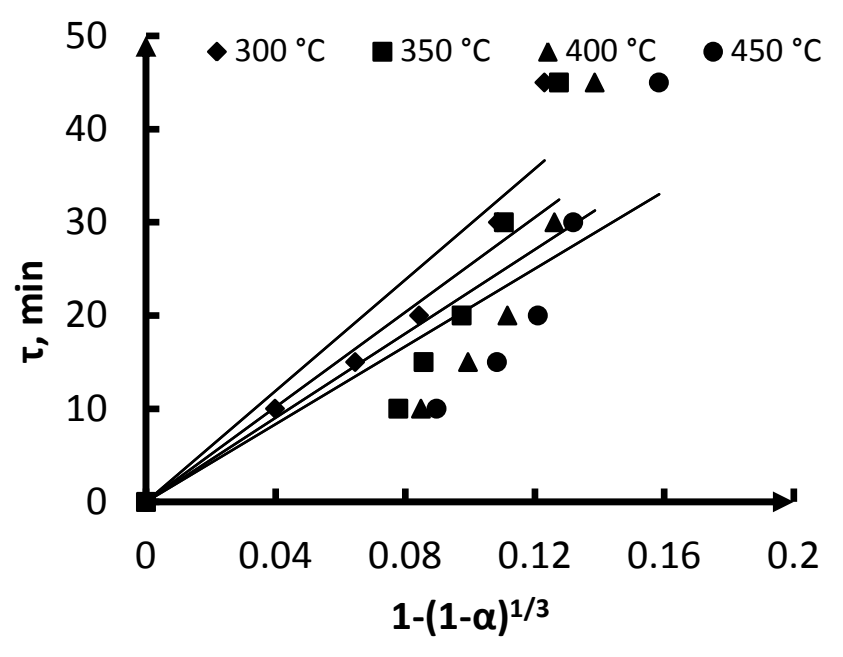

Fig. 7: Variation of time in minute with $1-(1-\alpha)^{1 / 3}$ at $300,350,400$ and $450{ }^{\circ} \mathrm{C}$.

\subsubsection{Pore Diffusion}

Assuming pore diffusion control, then the following equation should be obeyed:

$$
\tau=\frac{r_{o}^{2} * \rho}{6 b D_{e f f} C g}\left[1-3(1-\alpha)^{2 / 3}+2(1-\alpha)\right]
$$

This equation should yield a straight line when, $\tau$, is plotted against: $\left[1-3(1-\alpha)^{2 / 3}+2(1-\alpha)\right]$ as shown in figure 8 .

The straight lines obtained may be described by the following equations:

$$
\begin{gathered}
\tau_{300}=1030.6595\left[1-3(1-\alpha)^{2 / 3}+2(1-\alpha)\right], r=0.9782 \\
\tau_{350}=882.4082\left[1-3(1-\alpha)^{2 / 3}+2(1-\alpha)\right], r=0.9665 \\
\tau_{400}=708.5804\left[1-3(1-\alpha)^{2 / 3}+2(1-\alpha)\right], r=0.9483 \\
\tau_{450}=597.7025\left[1-3(1-\alpha)^{2 / 3}+2(1-\alpha)\right], r=0.9693
\end{gathered}
$$




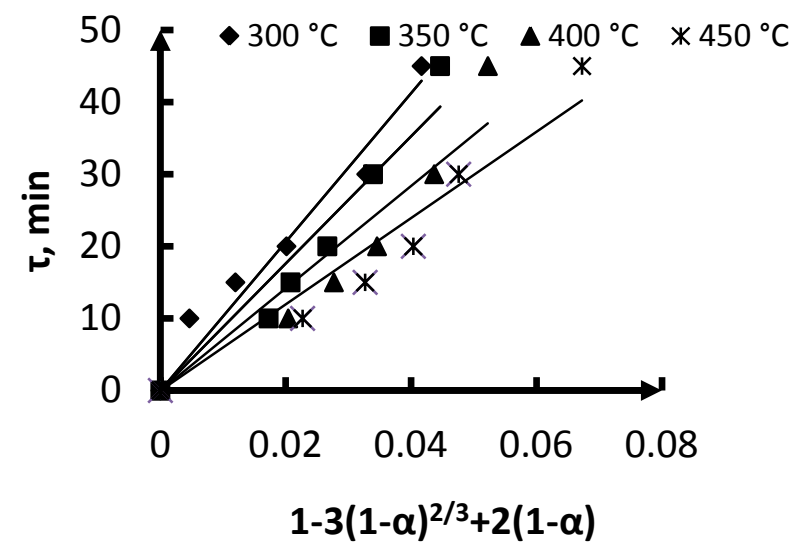

Fig. 8: Variation of time, in minute, with $\left[1-3(1-\alpha)^{2 / 3}+2(1-\alpha)\right]$

In this case, the correlation coefficient is higher compared with the respective values when convective diffusion and chemical reaction are assumed to govern the reoxidation process. The apparent activation energy of pore diffusion can be obtained by drawing $\ln D_{\text {eff }}$ against $\frac{10000}{T}$ as shown in figure 9. The straight line satisfies the formula:

$$
\begin{gathered}
\ln D_{\text {eff }}=\frac{-2170}{T}+3.5079, r=0.9964 \\
D_{\text {eff }}=33.3181 e^{-\frac{18041}{R T}}
\end{gathered}
$$

Hence, the apparent activation energy is:

$$
E=18041 \mathrm{~J} / \mathrm{mol}
$$

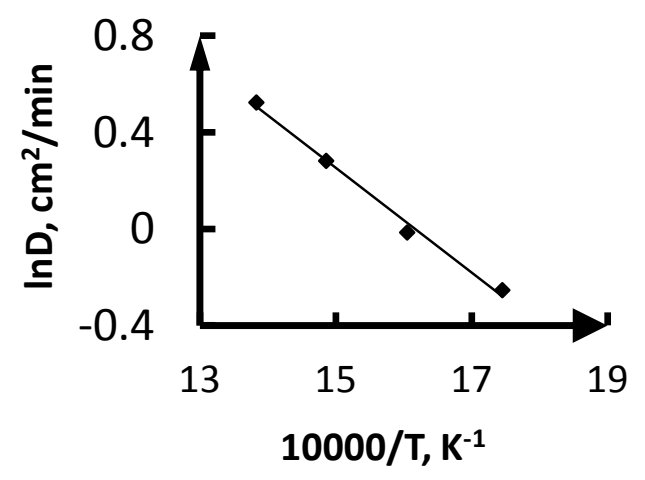

Fig. 9: Variation of diffusion coefficient with $\frac{10000}{T}$ according to Arrhenius equation.

The relationship between the effective diffusion coefficient and temperature can also be represented by:

$$
D_{\text {eff }}=3.4447 * 10^{-10} * T^{3.3884}
$$


The value of the exponent of $\mathrm{T}$ is larger than about two, which is the temperature exponent in the normal case of gas-solid reaction [28]. This may be attributed to changes in the pore structure of DRI during reoxidation. The effective diffusion coefficient is related to the product of porosity and labyrinth factor by the equation:

$$
D_{e f f}=D \varepsilon \lambda
$$

Therefore:

$$
\varepsilon \lambda=\frac{D_{e f f}}{D}
$$

The variation of the product of porosity and labyrinth factor can be expressed by the formula:

$$
\varepsilon \lambda=7 * 10^{-5} T-0.0174
$$

that indicates an increasing value of $\varepsilon \lambda$ with increasing temperature and consequently a growing effective diffusion coefficient.

Figure 10 shows the variation of assumed values of $\alpha$ with the time. The lines are calculated according to equation 22 and the corresponding measured points are superimposed on the calculated lines at 300 to $450^{\circ} \mathrm{C}$. The correlation coefficient is $r=$ $0.9983,0.9783,0.9645$ and 0.9648 at $300,350,400$ and $450^{\circ} \mathrm{C}$ respectively. The measured points do not deviate much from the calculated lines, indicating that pore diffusion is the step governing reoxidation of DRI under the present investigation conditions.

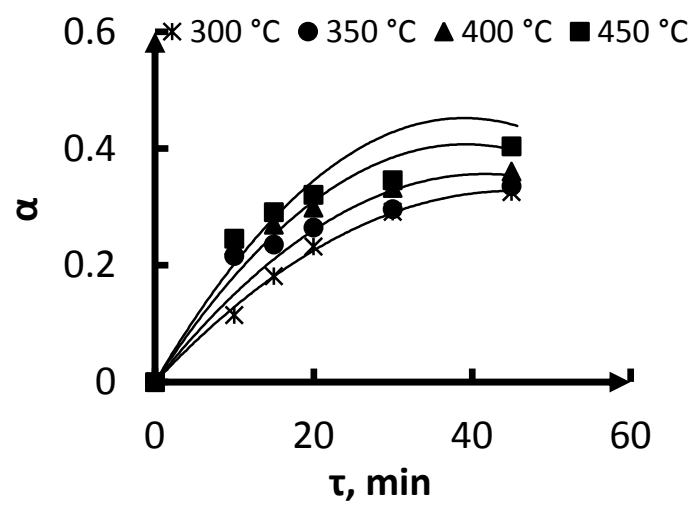

Fig. 10: Comparison of experimental data with calculated lines at 300, 350, 400 and $450^{\circ} \mathrm{C}$.

To ensure that the reoxidation process is controlled by pore diffusion in the present investigations, equation 23 can be modified as follows in equation 33: [29]

$$
\frac{1}{2}-\frac{\alpha}{3}-\frac{(1-\alpha)^{2 / 3}}{2}=\frac{D_{e f f} C g}{r_{o}^{2} \rho} \tau
$$


This equation should give a straight line when $\frac{1}{2}-\frac{\alpha}{3}-\frac{(1-\alpha)^{2 / 3}}{2}$ is plotted against the time, $\tau$. The result is shown in figure 11 for the above-mentioned 4 temperatures. The correlation coefficient ranges between 0.9261 and 0.9809 that is high enough to indicate the applicability of the diffusion model to the problem under investigation. The values of $D_{e f f}$ corresponding to each temperature can be calculated from the slopes of the straight lines.

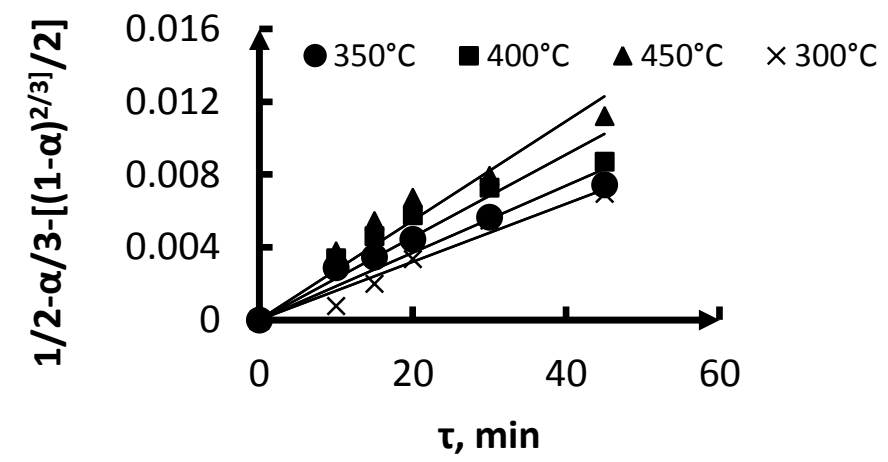

Fig. 11: Variation of $\frac{1}{2}-\frac{\alpha}{3}-\frac{(1-\alpha)^{2 / 3}}{2}$ with the time, $\tau$, min.

Figure 12 depicts the relationship between $D_{\text {eff }}$ and temperature. It can be described by the formula:

$$
D_{e f f}=5.3661 * 10^{-12} * T^{3.3510}
$$

As in the case of using the first model, the exponent of $T$ is higher than two, which could be the result of a change in the pore structure.

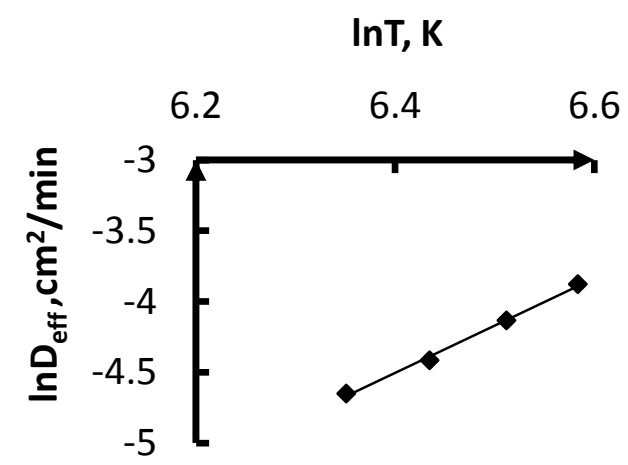

Fig. 12: Variation of diffusion coefficient with temperature in double logarithmic coordinates. 
The values of $\varepsilon \lambda$ corresponding to each temperature are calculated by equation $30 \mathrm{a}$ and plotted in figure 13, which shows the relation between $\varepsilon \lambda$ and temperature. The straight line follows the formula:

$$
\varepsilon \lambda=4.6048 * 10^{-7} * T^{1.636}
$$

\section{$\operatorname{lnT}, \mathrm{K}$}

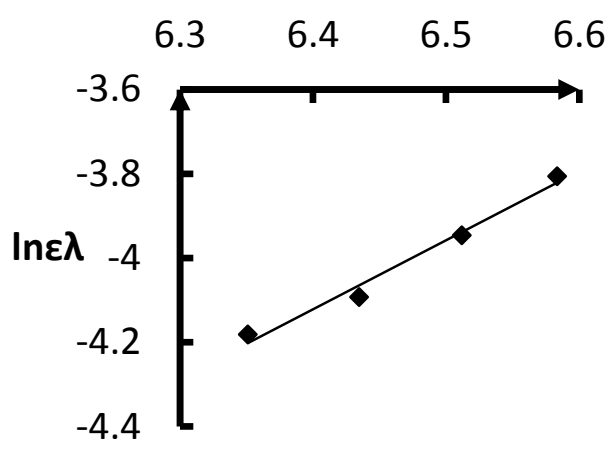

Fig. 13: Variation of $\varepsilon \lambda$ with temperature in double logarithmic coordinates.

Figure 14 shows the dependence of the degree of reoxidation on time. The lines are calculated by using equation 33 at different assumed values of $\alpha$ and substituting for $D_{\text {eff }}$ by equation 34 . The lines and the corresponding measured data agree within the range of tolerance in the experimental work. This is a supporting evidence for the applicability of the pore diffusion model to calculate the step governing the reoxidation process.

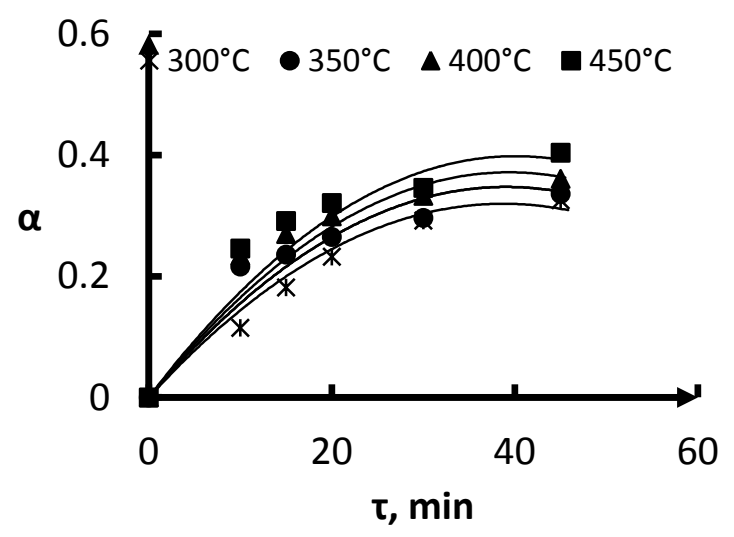

Fig. 14: Comparison of experimental data with calculated lines at 300, 350, 400 and $450^{\circ} \mathrm{C}$.

\section{Conclusions}

For studying the kinetics of DRI reoxidation in stagnant air at temperatures between 150 and $450^{\circ} \mathrm{C}$, two series of experiments were conducted; the first in the relatively low 
temperature range between 150 and $250^{\circ} \mathrm{C}$, and the second at higher temperature from 300 to $450^{\circ} \mathrm{C}$. The aim of the present research is to investigate the reoxidation reactions, which may take place in case of leakage in the transportation vessel of hot discharged DRI between the reduction shaft furnace and the electric arc furnace to make use of the sensible heat of hot DRI. Two mathematical models are used; the first includes the effects of surface diffusion, pore diffusion and chemical reaction at the gas-unreacted core interface and the second model treats the case of pore diffusion. The results can be summarized in the following:

1. In the low temperature range between 150 and $250^{\circ} \mathrm{C}$, the reoxidation process is governed by chemical reaction at the gas-unreacted core. The activation energy is $59.7 \mathrm{~kJ} / \mathrm{mol}$. No significant reoxidation occurred below $200^{\circ} \mathrm{C}$.

2. In the relatively higher temperature range between 300 to $450^{\circ} \mathrm{C}$, the reoxidation process proved to be controlled by pore diffusion.

3. The temperature exponent of the effective diffusion coefficient is 3.3884 , which are higher than the value of about two, normally appearing in gas-porous solid reactions, which might be due to changes in pore structure of the pellets.

4. The activation energy of diffusion is $18.04 \mathrm{~kJ} / \mathrm{mol}$.

5. In all cases, calculated and measured data are compared. They are in satisfactory agreement.

\section{ACKNOWLEDGEMENT}

The authors wish to thank AL-EZZ DEKHELLA STEEL Co. (EZDK) for providing the DRI pellets.

\section{REFERENCES}

[1] World Direct Reduction Statistics: "Direct from Midrex", $2^{\text {nd }}$ quarter, 8, (2017).

[2] Petrato, M.; Magnani, S.; Wurth, P.; Ravenscroft, C. and Hunter, R.: "Direct from midrex", $2^{\text {nd }}$ quarter, Italia, Genoa, 4, (2017).

[3] Usfin, Yu. S.: "Steel in the USSR", 12, 349, (1982).

[4] Shavrin, S. V.: "Steel in the USSR", 12, 354, (1982).

[5] Volovik, G. A.: "Steel in the USSR", 12, 355, (1982).

[6] Shkodin, K. K. and Manchinskii, V. G.: "Steel in the USSR", 12, 257, (1982).

[7] Shvedov, V. S.; Mikhalevich, A. G.; Moikin, V. I.; Svetlou, V. F.; Niktin, V. D. and Gusarov, A. K.: "Steel in the USSR", 9, 435, (1979).

[8] Kaushik, P. and Fruehan, R. J.: "Metallurgical and materials transactions B", 37B, 715, (2006).

[9] Kaushik, P. and Fruehan, R. J.: "Metallurgical and materials transactions B", 37B, 727, (2006).

[10] Wenzel, W. and Gudenau, H. W.: “Aufbereitungstechnik", 10, 705, (1969).

[11] Abdelmomen, S. S.: "Ironmaking and steelmaking", 41, 107, (2014).

[12] Pohl, U. and Schott, H. K.: "Investigations into the storage and handling capabilities of sponge iron briquettes", Proc. ECE Sem., Bucharest, Romania, ECE 24, May (1976).

[13] Grabke, H. J.; Steffen, R. and Jess, A.: "Reoxidation and ignition behavior of DRI to improve safety", European Commission, EUR, Luxembourg, 1, (2003).

[14] Quintero, R.: “Metall. plant technol.”, 4, 38, (1981). 
[15] Abel, M.; Hein, M.; Böhm, C.; Sterrer, W. and Vaillancourt, D.: "Direct from midrex", $4^{\text {th }}$ quarter, 6, (2014).

[16] Razza, P. and Patrizio, D.: "Steel making and casting", 39, (2010).

[17] Mardosevich, V. A. and Pchelkin, S. A.: "Steel in the USSR", 10, 252, (1980).

[18] Yanez, D. and Scarnati, T. M.: "Metallurgical plant and technology international", Monterrey, Mexico 4, 42, (1992).

[19] Opadhya, K.: "Journal of metals", 39, October (1984).

[20] Levenspiel, O.: "Chemical Reaction Engineering, An introduction to the design of chemical reactors", $5^{\text {th }}$ edition, eds. by J. Wiley and Sons, Inc., New York, London, Sydney, pp. 338-352, (1967).

[21] Mukhlyonov, I.; Averbukh, A.; Tumarkina, E. and Furmer, I.: "Chemical Technology, Part 1", Mir Publishers, Moscow, 215, (1979).

[22] Kutepov, A. M.; Bonddareve, T. I. and Berengarten, M. G.: Basic "Chemical engineering with practical applications”, Mir publishers, Moscow, pp. 64-81, (1988).

[23] Szekely, J. \& Nickolas and Themelis, J.: "Rate phenomena in Process Metallurgy", Eds. By Wiley- Interscience, a Division of J. Wiley and Sons, Inc., New York, London, Sydney, Toronto, pp. 620-623, (1971).

[24] Smith, J. M.: "Chemical engineering kinetics", $2^{\text {nd }}$ edition, International Student Edition, Mc Graw Hill, Kugakusha, LTD, Tokyo, Düsseldorf, Johannesburg, London, pp. 571-582, (1970).

[25] Bandopadhyay, A.; Ganguly, A.; Prasad, K. K.; Sakar, S. B. and Ray, H. S.: "ISIJ international", 29, 753, (1989).

[26] Biswas, A. K.: "Principles of blast furnace ironmaking theory and practice", First Indian Edition, SBA Replications, Calcutta, 37, (1984).

[27] Ref. 24, 387.

[28] Geiger, G. H. and Pairier, D. R.: "Transport phenomena in metallurgy", Addison Wesely Publishing Company, Menlo Park- California-London-Don Mills-Ontario, 467, (1973).

[29] Bogdandy, L. V. and Engell, H. J.: "The reduction of iron ores", Verlag Stahleisen m.b.H. Düsseldorf, Springer-Verlag Berlin, Heidelberg, New York, 127, (1971).

\section{LIST OF SYMBOLS}

b: number of moles of $\mathrm{O}_{2}$ needed to reoxidize one mole of $\mathrm{Fe}$ to $\mathrm{Fe}_{2} \mathrm{O}_{3}$, according to the reaction (3)

$\mathrm{C}_{\mathrm{g}}$ : concentration of $\mathrm{O}_{2}$ in air at the test temperature, $\frac{\mathrm{mol}}{\mathrm{cm}^{3}}$

D: Diffusion coefficient of oxygen in air, $\mathrm{cm}^{2} / \mathrm{s}$, according to equation 16 .

$D_{\text {eff }}$ Diffusion coefficient of oxygen in the pores of the pellet $\mathrm{cm}^{2} / \mathrm{min}$, according to equations $22,27,28,30,31,33,34$.

$E$ : Apparent activation energy of chemical reaction $\mathrm{J} / \mathrm{mol}$, according to equation 9.

$E$ : Apparent activation energy, $\mathrm{J} / \mathrm{mol}$ of pore diffusion, according to equations $28,29$.

$\mathrm{k}$ : rate constant of chemical reaction, $(\mathrm{cm} / \mathrm{min})$ according to equations $2,8,9$.

$M_{\text {air }}, M_{\mathrm{O}_{2}}$ : Molecular weights of air and $\mathrm{O}_{2}$, respectively, according to equation 17.

$P$ : Pressure, atm, according to equation 17.

$\mathrm{R}$ : universal gas constant, $\mathrm{J} / \mathrm{k} \mathrm{mol}=8.314 \mathrm{~J} / \mathrm{k} \mathrm{mol}$

$r$ : correlation coefficient

$\mathrm{r}_{\mathrm{o}}$ : initial radius of the pellet, $\mathrm{cm}$, according to equations $2,9,10,22,33$.

$\mathrm{T}$ : absolute temperature, $\mathrm{K}$ 
$\tau$ : time, min, according to equations $2,5-7,10-14,18-21,33$.

$v_{\text {air }}, v_{\mathrm{O}_{2}}$ : Molar volumes of air and $\mathrm{O}_{2}$, respectively, according to equation 17.

$\alpha$ : Degree of reoxidation according to equations 2, 4, 10-14, 18-26, 33.

$\beta$ : Mass transfer coefficient, $\mathrm{cm} / \mathrm{min}$, according to equations 10,15 .

$\delta$ : Thickness of the gaseous boundary layer, $\mathrm{cm}$, according to equations 15,17 .

$\varepsilon$ : Porosity of the pellet, according to equations $31,31 \mathrm{a}, 32$.

$\lambda$ : labyrinth factor, according to equations $31,31 \mathrm{a}, 32$.

$\rho:$ molar density of Fe in DRI (mole/ $\left.\mathrm{cm}^{3}\right)$ according to equations 2, 10, 22, 33. 